\title{
Experimental Colitis Is Associated with Ultrastructural Changes in Inflamed and Uninflamed Regions of the Gastrointestinal Tract
}

\author{
Azhar M. Bou-Fersen ${ }^{a} \quad$ Jehoram T. Anim ${ }^{b}$ Islam Khan ${ }^{a}$ \\ Departments of ${ }^{\mathrm{a} B i o c h e m i s t r y}$ and ${ }^{\mathrm{b}}$ Pathology, Faculty of Medicine, Health Sciences Center, Kuwait University, \\ Kuwait
}

\section{Key Words}

Inflammatory bowel diseases $\cdot$ Mitochondria .

Endoplasmic reticulum • Golgi apparatus •

Myeloperoxidase $\cdot$ Malondialdehyde

\begin{abstract}
Objectives: The objective of this study was to examine the ultrastructural changes in cell organelles such as mitochondria, endoplasmic reticulum (ER) and Golgi apparatus in inflamed colon and uninflamed ileum in colitic rats. Materials and Methods: Colitis was induced in rats by intracolonic administration of trinitrobenzenesulfonic acid (TNBS). The animals were sacrificed on day 5 after TNBS administration and colonic and ileal samples were used for estimation of myeloperoxidase (MPO) activity, malondialdehyde (MDA) concentration, histologic examination and transmission electron microscopy. Results: TNBS caused a significant reduction in body weight and an increase in MPO activity in colonic, but not in the ileal samples in animals with colitis. MDA levels were increased both in inflamed colon and the uninflamed ileal segments in colitis. Electron microscopy revealed swelling of mitochondria with broken cristae and disruption of the inner membrane. Colitis also caused fragmentation of the ER with loss of ribosomes and swelling of the Golgi apparatus with distended vesicles in both smooth muscle and epithelial cells in the ileal and colonic segments. These changes were absent in the control rats without colitis. Con-
\end{abstract}

clusions: These findings demonstrate ultrastructural deformities in both the mucosa and smooth muscle in inflamed and uninflamed regions of the gastrointestinal tract in experimental colitis. The structural changes in mitochondria are responsible for reduced ATP, while abnormalities in the ER and the Golgi apparatus may explain a generalized effect on protein synthesis, trafficking and targeting mechanisms, and may account for physiological changes seen in experimental colitis.

Copyright $\odot 2008$ S. Karger AG, Basel

\section{Introduction}

Inflammatory bowel diseases (IBDs) such as Crohn's disease (CD) and ulcerative colitis (UC) are among the most chronic inflammatory conditions [1]. Although various chemical, genetic, infectious and dietary factors have been implicated, the exact etiology of IBDs remains unknown [2]. Changes in IBDs are primarily localized to the mucosa and submucosa, but the neuromuscular apparatus is also involved [3]. These conditions are the most debilitating disorders which are associated with a decreased food intake and defective absorption of nutrients from the inflamed gastrointestinal (GI) tract [4-6]. Although damage due to inflammation may be localized, regions of the GI tract which are not overtly inflamed also show functional changes [7]. We have earlier report-

Dr. Islam Khan, $\mathrm{PhD}$

Faculty of Medicine, Health Sciences Center

Kuwait University, PO Box 24923

13110 Safat (Kuwait)

Tel. +965 531 2300, Fax +965 533 8908, E-Mail islam@hsc.edu.kw 
ed a decrease in ATP concentrations in the inflamed colon [8], which may be due to decreased activity of ATP synthase in CD and UC patients [9]. Although earlier studies have reported alteration in the activity of lysosomal enzymes in IBDs, changes in the marker enzymes of peroxisome, endoplasmic reticulum (ER), plasma membrane, mitochondria and cytosol were not evident [10-12]. Since mitochondria are an important source of superoxide anions $\left(\mathrm{O}_{2}^{-}\right)$which are increased in IBDs, damage in mitochondrial structure is likely to occur. Therefore, we hypothesize that a decrease in ATP concentrations is due to changes in mitochondrial structure. To find out whether such changes are specific to inflammation, structural changes were also examined in the uninflamed ileum of rats with colitis in this study. Furthermore, IBD is associated with induction of a large number of inducible and housekeeping genes, in addition to alterations in protein translation and modification, indicating deregulation of the protein synthesis, modification and trafficking mechanisms [13]. Therefore, it was also important to look into structural changes in the ER and Golgi apparatus.

The primary aim of this study was to investigate ultrastructural changes in mitochondria, ER and Golgi apparatus using transmission electron microscopy in inflamed colon and uninflamed ileum from rats having colitis induced by trinitrobenzenesulfonic acid (TNBS).

\section{Materials and Methods}

\section{Induction of Colitis}

Male Sprague-Dawley rats weighing between 150 and $250 \mathrm{~g}$ used in this study were kept in a controlled environment. These animals were bred and maintained by the Animal Resource Center, Faculty of Medicine, Kuwait University, Kuwait. The animals were given free access to a standard rodent chow (Special Diet Services, UK) and water ad libitum.

Colitis was induced following a standard method by intrarectal administration of TNBS [14-17]. Briefly, rats lightly anesthetized with diethyl ether (APS, Finechem, Sydney, Australia) received an aliquot of $0.5 \mathrm{ml}$ of $50 \%$ ethanol containing $30 \mathrm{mg}$ TNBS intrarectally through a catheter inserted up to approximately $8 \mathrm{~cm}$ from the anal margin. The animals were sacrificed on the 5th day after TNBS administration. Control animals received phosphate-buffered saline only (Sigma, St. Louis, Mo., USA) in a similar manner. Body weights (BWs) of both control and treated animals were recorded before and after the induction of colitis.

\section{Myeloperoxidase Activity Assay}

Myeloperoxidase (MPO) is a biochemical marker of neutrophil infiltration into intestinal tissues and was used to confirm colitis. The method was essentially the same as described earlier [16-19]. MPO activity was expressed as units per milligram tis- sue, where a unit is defined as nanomoles of $\mathrm{H}_{2} \mathrm{O}_{2}$ converted to product per minute per milligram tissue.

\section{Malondialdehyde Estimation}

Malondialdehyde (MDA) is used as a marker of lipid peroxidation $[17,19]$. MDA was estimated to indicate peroxide damage to membrane caused by inflammation. The tissue homogenates which were prepared for MPO assay were used for MDA estimation following methods as used previously [19]. The concentration of MDA was expressed as nanomoles per milligram tissue.

\section{Histological Methods}

Colitis was also confirmed by histology. For this purpose, segments of colon and ileum were collected from the control and colitic rats and cleaned with cold phosphate-buffered saline. Then the segments were cut into small pieces of $0.5-1.0 \mathrm{~cm}$ and immersed directly in a $4 \%$ buffered formaldehyde solution as fixative, containing $32.6 \mathrm{mM}$ monobasic sodium phosphate (MCB, USA) and $42.26 \mathrm{~mm}$ dibasic anhydrous sodium phosphate (AR, USA) and left overnight. The fixed tissues were processed routinely into paraffin and 5 - $\mu \mathrm{m}$ sections were stained routinely with hematoxylin and eosin. The tissue sections were examined for evidence of inflammation and the severity of inflammation was graded on a scale of 1-5 following criteria described earlier [17].

Transmission Electron Microscopic Analysis

The colonic and ileal segments taken from the noncolitic control and colitic rats were cut into small pieces and processed for transmission electron microscopic analysis. Very tiny pieces from them were fixed in 3\% glutaraldehyde in Millonig's buffer for $3 \mathrm{~h}$, and then washed in Millonig's phosphate buffer containing $\mathrm{NaH}_{2} \mathrm{PO}_{4} \times 2 \mathrm{H}_{2} \mathrm{O}$ and $\mathrm{NaOH}(\mathrm{pH}$ 7.3). Postfixation was done using osmium tetroxide, and the tissues were processed routinely for transmission electron microscopic analysis using araldite as embedding medium (Lynx electron microscope tissue processor). Ultrathin sections $(155 \mathrm{~nm})$ were stained with uranyl acetate and lead citrate, and examined using a JEOL 1200 EXII electron microscope.

Statistical Analysis

Data are presented as mean $\pm S D$ and ' $n$ ' represents the number of animals used. Data were analyzed using GraphPad Prism (GraphPad Software Inc.). Significance was calculated using the t test, and $p<0.05$ was considered statistically significant.

\section{Results}

\section{Induction of Colitis}

Colitis was confirmed by measuring several parameters including BW, MPO activity, MDA concentration, and by histological evaluation. The BW decreased significantly $(\mathrm{p}<0.0001)$ by $13.4 \pm 0.7 \%(\mathrm{n}=25)$ in the colitic animals as compared to their day 0 weights (fig. 1). On the contrary, the noncolitic control animals gained weight by $9.0 \pm 0.7 \%(n=25)$ as compared to their starting weights at day 0 (fig. 1). 


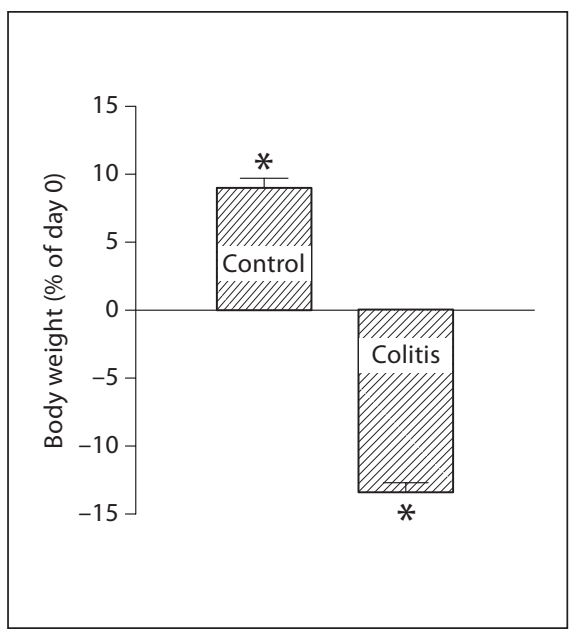

Fig. 1. Bar diagram showing changes in BW (percentage of day 0) of the control and colitic rats 5 days after TNBS administration. Data are mean $\pm \mathrm{SD}$. The asterisks indicate significance versus day $0(\mathrm{p}<$ $0.0001, \mathrm{n}=25$ ).

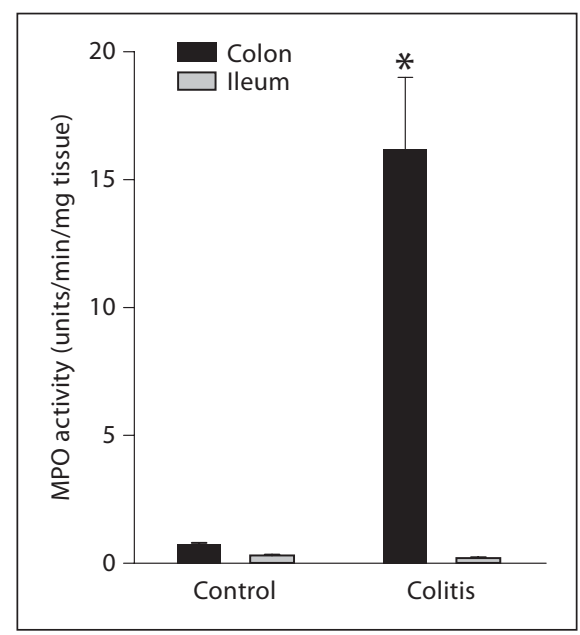

Fig. 2. MPO activity (units/min/mg tissue) in the indicated tissue segments from the control and colitic rats. Data are mean $\pm \mathrm{SD}$. The asterisk indicates significance $(\mathrm{p}<0.0001, \mathrm{n}=24)$.

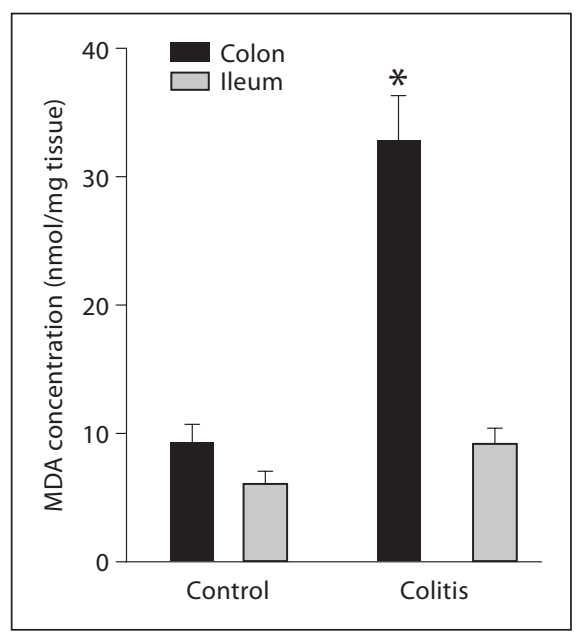

Fig. 3. MDA levels (nmol/mg tissue) in the indicated tissue segments from the control and colitic rats. Data are mean $\pm \mathrm{SD}$. The asterisk indicates significance $(\mathrm{p}<0.0001$ vs. the controls, $n=29$ ).

\section{MPO Activity}

MPO activity was $16.2 \pm 2.8$ units $/ \mathrm{min} / \mathrm{mg}$ tissue in inflamed colonic segments from colitic rats $(n=24)$ which was significantly $(\mathrm{p}<0.0001, \mathrm{n}=24)$ higher as compared to $0.8 \pm 0.03$ units $/ \mathrm{min} / \mathrm{mg}$ tissue in the colonic segments from the noncolitic control rats (fig. 2).

On the other hand, MPO activity was $0.3 \pm 0.03$ units/ $\mathrm{min} / \mathrm{mg}$ tissue in the ileal segments from colitic rats ( $\mathrm{n}=$ $21)$, and was not statistically different $(p>0.05)$ from $0.199 \pm 0.036 \mathrm{units} / \mathrm{min} / \mathrm{mg}$ tissue in the control rats (fig. 2).

\section{MDA Level}

The concentration of MDA was $32.8 \pm 3.5 \mathrm{nmol} / \mathrm{mg}$ tissue $(\mathrm{n}=29)$ in the inflamed colonic segments, and was significantly $(\mathrm{p}<0.0001)$ higher than $9.3 \pm 1.38 \mathrm{nmol} /$ $\mathrm{mg}$ tissue in the uninflamed colonic segments from the control rats (fig. 3).

MDA levels $(9.18 \pm 1.23 \mathrm{nmol} / \mathrm{mg}$ tissue, $\mathrm{n}=32)$ in uninflamed ileal segments from the colitic rats were also higher $(\mathrm{p}=0.059)$ as compared to those $(6.06 \pm 0.99$ $\mathrm{nmol} / \mathrm{mg}$ tissue, $\mathrm{n}=32$ ) in the control rats (fig. 3 ).

\section{Histology}

The severity of colitis was graded on a scale of 1-5 using the criteria described earlier [17]. This was based on the infiltration by inflammatory cells, the extent of tissue
Table 1. Inflammation grades seen in colitic animals used in this study

\begin{tabular}{lll}
\hline Grades & $\begin{array}{l}\text { Noncolitic control } \\
\text { rats }(\mathrm{n}=24)\end{array}$ & $\begin{array}{l}\text { Colitic rats } \\
(\mathrm{n}=24)\end{array}$ \\
\hline 0 & $24 / 24$ & $0 / 24$ \\
1 & $0 / 24$ & $2 / 24$ \\
2 & $0 / 24$ & $5 / 24$ \\
3 & $0 / 24$ & $7 / 24$ \\
4 & $0 / 24$ & $5 / 24$ \\
5 & $0 / 24$ & $5 / 24$ \\
\hline
\end{tabular}

damage and necrosis. The colitic animals in the present experimental conditions showed all 5 grades of inflammation (fig. 4a; table 1), whereas the noncolitic rat colon showed normal mucosa, submucosa, muscularis propria and serosa (fig. 4b). Ileal tissues taken from the colitic rats could not be distinguished from those taken from the noncolitic control rats, and did not show any sign of inflammation under the light microscope (fig. 4c).

\section{Transmission Electron Microscopic Analysis}

There was swelling of mitochondria with abnormal cristae both in epithelial and smooth muscle cells of the colonic (fig. 5a, b) and ileal samples (fig. 6a, b). The mito- 
chondria were normal in the ileal and colonic segments of noncolitic rats (fig. 5c). Furthermore, the normal ER in noncolitic animals (fig. 5d) was fragmented in inflamed colonic epithelial cells (fig. 5e). Swelling of the Golgi apparatus (fig. 5f) which appeared to be surrounded by distended vesicles was also evident, indicating subcellular damage.

Similar changes were also observed in ileal epithelial and smooth muscle cells from the colitic animals (fig. 6ac). These organelles were different than the normal-looking organelles in noncolitic rat ileum (fig. 6d).

\section{Discussion}

IBDs such as CD and UC are idiopathic conditions characterized by deregulation of immune reactions. We have earlier reported a decrease in purine (ATP, ADP and AMP) concentration in experimental colitis [8]. Oxidative phosphorylation is an important mitochondrial function for the production of ATP. Since structural integrity of mitochondria is important for their functioning, a decrease in ATP could be due to disruption in mitochondrial structure. The ER and Golgi apparatus are important sites for protein synthesis and modification, but whether there are any changes in their structure remains poorly addressed. However, it is well established that smooth muscle plays an active role in inflammation, and that the uninflamed part of the GI tract also shows altered functions in colitis [7]. Therefore, in this study we examined ultrastructural changes in mitochondria, ER and Golgi apparatus using transmission electron microscopy in both muscle and mucosa in inflamed colon and noninflamed ileum from rats which had received TNBS 5 days earlier. Thus, the focus of discussion will be on the confirmation of inflammation in the tissues used, and ultrastructural changes associated with colitis. An attempt will also be made to explain possible implications of the ultrastructural changes in relation to altered physiology reported in IBDs.

In this study, we have used an acute model of experimental colitis induced by TNBS administered intracolonically. The present model was developed by Morris et al. [14], and has been used by us and others extensively. The animals used in this study received TNBS 5 days earlier. This condition was chosen because at that point we had already reported maximum inflammatory responses in terms of histopathology and MPO activity [17-19]. Since uninflamed ileum in colitic animals is
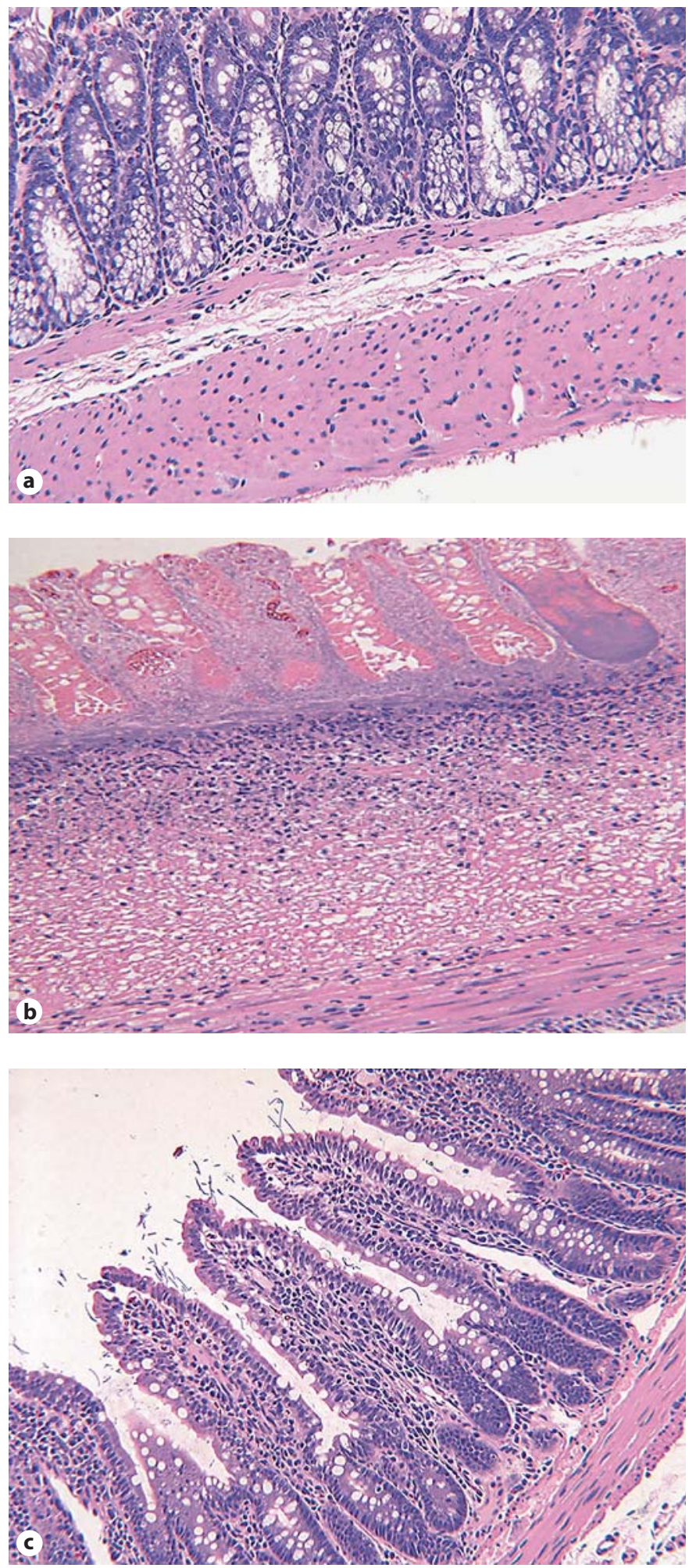

Fig. 4. Representative hematoxylin-and-eosin-stained sections of control colon (magnification $\times 100)(\mathbf{a})$, inflamed colon (magnification $\times 250)(\mathbf{b})$, and ileum from colitic animals (magnification $\times 250)(\mathbf{c})$. 

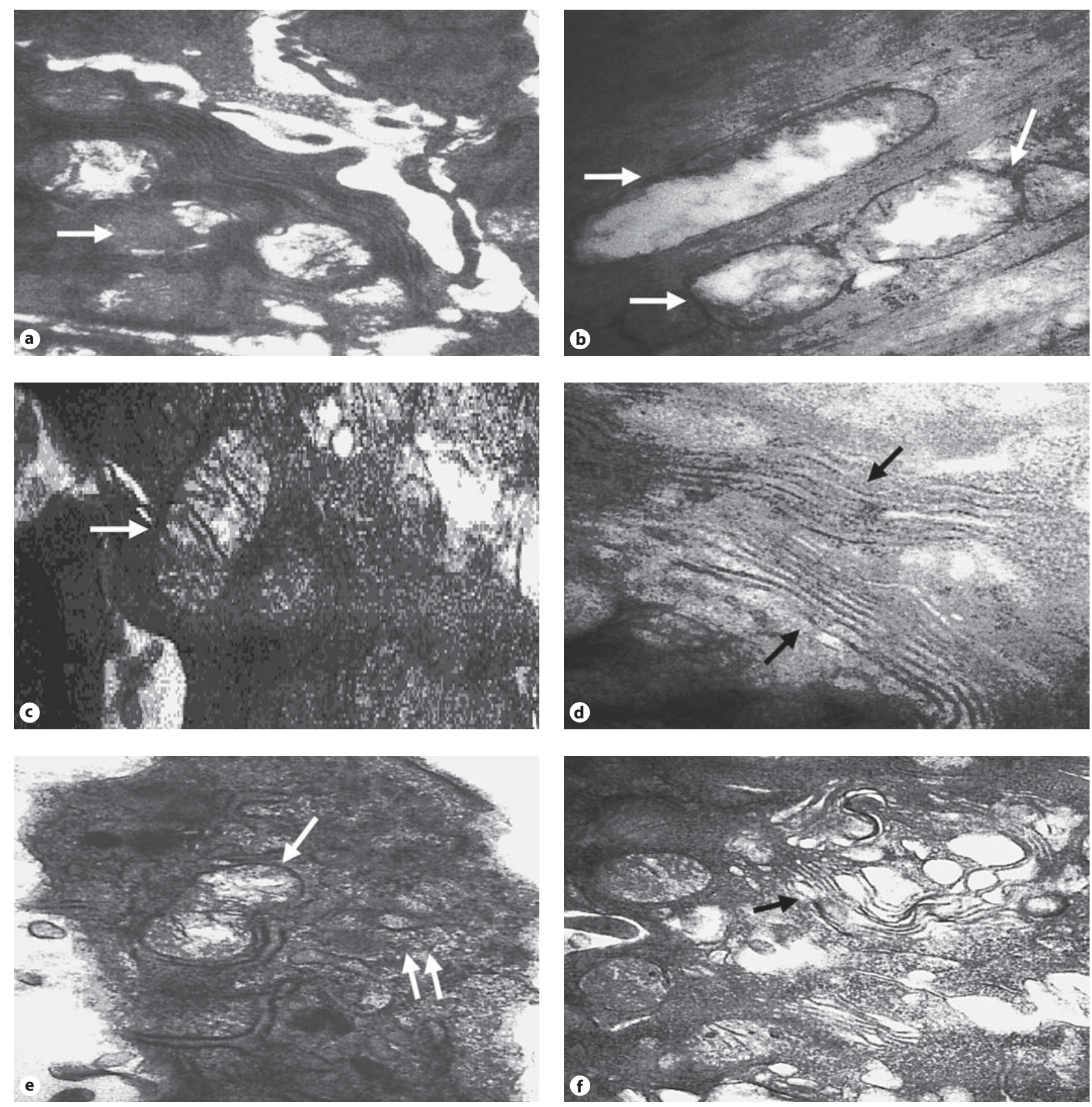

Fig. 5. Transmission electron microscopy showing an abnormal mitochondrion (arrow) in the epithelial layer of the colitic rat colon $(\times 20,000)(\mathbf{a})$, abnormal mitochondria (arrows) in the muscle layer of the colitic rat colon $(\times 20,000)(\mathbf{b})$, a normal mitochondrion (arrow) in the noncolitic rat colon $(\times 30,000)(\mathbf{c})$, normal ER (arrows) in the control noncolitic rat colon $(\times 20,000)(\mathbf{d})$, abnormal fragmented ER (double arrow) and an abnormal mitochondrion (single arrow) in the inflamed rat colon $(\times 15,000)(\mathbf{e})$, and an abnormal Golgi complex (arrow) in the inflamed rat colon $(\times 15,000)(\mathbf{f})$. Values in parentheses indicate magnification. 

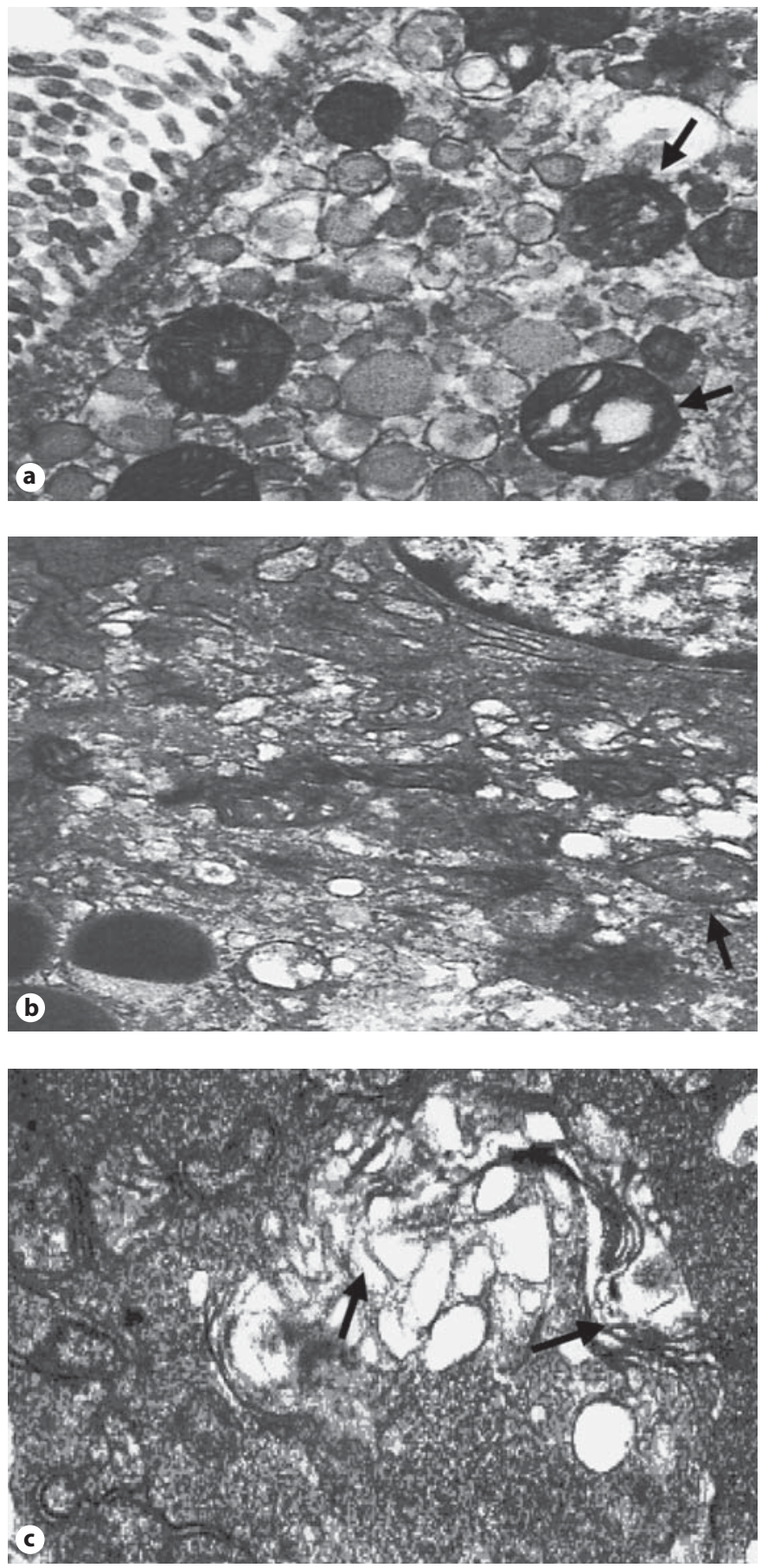

Fig. 6. Transmission electron microscopy showing abnormal mitochondria (arrows) in the epithelial layer of the ileal segment from the colitic rat $(\times 15,000)(\mathbf{a})$, an abnormal mitochondrion (arrow) in the muscle layer of the ileal segment from the colitic rat $(\times 15,000)(\mathbf{b})$, and an abnormal Golgi apparatus (arrows) in the ileal segment from the colitic rat $(\times 15,000)(\mathbf{c})$. Values in parentheses indicate magnification. known to show functional changes [7], both the inflamed colon and uninflamed ileum from the animals with colitis were studied. However, before examining the ultrastructural changes, it was necessary to confirm the presence of colitis in the animals used in this study. The animals showed reduction in BW, increased MPO activity and MDA concentrations in the inflamed colonic tissue. On the other hand, these changes were not evident in the ileum of the rats with colitis. Interestingly, MDA concentration was elevated in the ileal segments, indicating upregulation of peroxidation in the uninflamed ileum. Microscopically the colonic samples showed inflammation ranging from grade 1 to grade 5 (table 1), whereas ileal histology was normal in the same colitic rats. Taken together these findings confirm the presence of inflammation in the colon, but not in the ileum of the rats used in this study. These findings thus suggest that altered functions in the uninflamed ileum are not associated with overt biochemical or microscopic changes.

The basis of this study came from our earlier findings showing reduction in ATP content in the inflamed colon [8]. One possible explanation for the reduced ATP may be changes in mitochondrial structure. For this purpose, we have examined ultrastructural changes in both colonic and ileal segments of the animals which showed all grades (grade 1-5) of inflammation in their colon. However, the results presented here are from grade 5 colonic inflammation because ultrastructural changes were similar for all grades of inflammation observed in this study. These included swelling of mitochondria with disruption of cristae both in the inflamed colon and uninflamed ileum. The cristae harbor various enzymes required for oxidative phosphorylation, thus these structural deformities may explain reduction in ATP contents in the inflamed colon [8]. It is worth mentioning that reduction in ATP synthase which synthesizes ATP has been reported earlier in IBD patients [9]. Our findings add further support to the earlier observations, and suggest that ATP reduction could be due to mitochondrial damage in inflamed colon. The changes in mitochondrial structure were evident in both mucosal epithelial cells and smooth muscle cells in the bowel wall. Interestingly, the ileum, which is uninflamed, also showed similar abnormalities in mitochondrial structure in the colitic rats. Thus, although colitis was localized to the colon, uninflamed parts of the GI tract are also involved at the ultrastructural level, which might explain the functional changes reported in the uninflamed ileum in IBDs [7]. Mitochondria also participate

Med Princ Pract 2008;17:190-196 
in apoptosis, which is induced by oxidative damage to their membrane. This may further add to the roles of mitochondria in the pathogenesis of IBDs. Our findings also demonstrate damage to the ER and changes in the Golgi apparatus in both the colon and ileum of rats with colitis. These organelles participate in protein synthesis and modification for targeting of various proteins to different locations. IBD is associated with induction of a large number of genes regulated by NFkB. Therefore, enlargement of the Golgi apparatus might suggest overactivity to cope with inflammatory responses. Furthermore, the ER is also an important source of intracellular $\mathrm{Ca}^{2+}$ for muscle contraction which is reduced in inflamed colon [17-22]. We predict that ER structural changes may, partly, be responsible for motility alterations in IBD.

\section{Conclusion}

We have demonstrated structural changes in mitochondria, ER and Golgi organelles in the mucosal and muscle layers of both the inflamed colon and uninflamed ileum of colitic animals. The structural changes in mitochondria are responsible for reduced ATP, while abnormalities in the ER and Golgi apparatus may explain a generalized effect on protein synthesis, trafficking and targeting mechanisms, and may account for physiological changes seen in experimental colitis.

\section{Acknowledgements}

Financial support was received from Kuwait University Research Administration grant YM01/05, and we thank Miss Amna Al-Shamali for technical assistance.

\section{References}

1 Viscido A, Aratari A, Maccioni F, Signore A, Caprilli R: Inflammatory bowel diseases: clinical update of practical guidelines. Nucl Med Commun 2005;26:649-655.

$\checkmark 2$ Fiocchi C: Inflammatory bowel disease pathogenesis: therapeutic implications. Chin J Dig Dis 2005;6:6-9.

3 Mawe GM, Collins SM, Shea-Donohue T: Changes in enteric neural circuitry and smooth muscle in the inflamed and infected gut. Neurogastroenterol Motil 2004; 16 (suppl 1):133-136.

4 Gassull MA, Cabre E: Nutrition in inflammatory bowel disease. Curr Opin Clin Nutr Metab Care 2001;4:561-569.

5 McHugh KJ, Weingarten HP, Keenan C, Wallace JL, Collins SM: On the suppression of food intake in experimental models of colitis in the rat. Am J Physiol 1993;264:871876.

- 6 McHugh K, Castonguay TW, Collins SM, Weingarten HP: Characterization of suppression of food intake following acute colon inflammation in the rat. Am J Physiol 1993; 265:R1001-R1005.

7 Jacobson K, McHugh K, Collins SM: The mechanism of altered neural function in a rat model of acute colitis. Gastroenterology 1997;112:156-162.

-8 Al-Awadi FM, Khan I: Blood purine and energy status in rats with colitis. Dig Dis Sci 2001;46:443-448.
Schurmann G, Bruwer M, Klotz A, Schmid KW, Senninger N, Zimmer KP: Transepithelial transport processes at the intestinal mucosa in inflammatory bowel disease. Int J Colorectal Dis 1999;14:41-46.

10 O’Morain C, Smethurst P, Levi AJ, Peters TJ: Organelle pathology in ulcerative and Crohn's colitis with special reference to the lysosomal alterations. Gut 1984;25:455459.

11 O’Morain C, Smethurst P, Levi J, Peters TJ: Subcellular fractionation of rectal biopsy homogenates from patients with inflammatory bowel disease. Scand J Gastroenterol 1985; 20:209-214

12 Fagundes-Neto U, Wehba J, Viaro T, Machado NL, Patricio FR: Protracted diarrhea in infancy: clinical aspects and ultrastructural analysis of the small intestine. J Pediatr Gastroenterol Nutr 1985;4:714-722.

13 Zhang K, Kaufman RJ: Protein folding in the endoplasmic reticulum and the unfolded protein response. Handb Exp Pharmacol 2006;172:69-91.

14 Morris GP, Beck PL, Herridge MS, Depew WT, Szewczuk MR, Wallace JL: Hapten-induced model of chronic inflammation and ulceration in the rat colon. Gastroenterology 1989;96:795-803.

15 Khan I, Al-Awadi FM: Colonic muscle enhances the production of interleukin-1 beta messenger RNA in experimental colitis. Gut 1997;40:307-312.
6 Khan I, Al-Awadi FM, Abul H: Colitis-induced changes in the expression of the $\mathrm{Na}^{+}$/ $\mathrm{H}^{+}$exchanger isoform NHE-1. J Pharmacol Exp Ther 1998;285:869-875.

17 Khan I, Oriowo MA, Anim JT: Amelioration of experimental colitis by $\mathrm{Na}-\mathrm{H}$ exchanger- 1 inhibitor amiloride is associated with reversal of IL-1 $\beta$ and ERK mitogen-activated protein kinase. Scand J Gastroenterol 2005;40: 578-585.

18 Bradley PP, Priebat DA, Christensen RD, Rothstein G: Measurement of cutaneous inflammation: estimation of neutrophil content with an enzyme marker. J Invest Dermatol 1982;78:206-209.

19 Al-Jarallah A, Khan I, Oriowo MA: Mechanism of reduced colonic contractility in experimental colitis: role of sarcoplasmic reticulum pump isoform-2. Mol Cell Biochem 2007;1-2:169-178.

20 Ohkawa H, Ohishi N, Yagi K: Assay for lipid peroxides in animal tissues by thiobarbituric acid reaction. Anal Biochem 1979;95:351358.

21 Iseri SO, Sener G, Saglam B, Gedik N, Ercan F, Yegen BC: Oxytocin ameliorates oxidative colonic inflammation by a neutrophil-dependent mechanism. Peptides 2005;26:483491.

22 Grossi L, McHugh K, Collins SM: On the specificity of altered muscle function in experimental colitis in rats. Gastroenterology 1993;104:1049-1056. 